\title{
Increase of Voltage Quality in Industrial Distribution Systems
}

\author{
M. Cernan, Z. Muller and J. Tlusty
}

\author{
Department of Electrical Power Engineering \\ Faculty of Electrical Engineering, Czech Technical University \\ Technicka 2, 16627 Prague (Czech Republic) \\ Phone/Fax number:+420 224352 138/+420 233337 556, e-mail: martin.cernan@fel.cvut.cz, \\ zdenek.muller@fel.cvut.cz, tlusty@fel.cvut.cz
}

\begin{abstract}
This paper deals with the solution of the issue of exceeding the permissible levels for long-term flicker effect $P_{l t}$ in industrial distribution systems. Flicker effect in distribution systems is often exceeded as a result of the connection of electric arc furnaces, which exhibits high variable electrical power in-take. The article shows the benefits of measures on the steel plants, the distribution system operator and the transmission system operator. The main benefits were the installation SVC device and reconstruction of substation $220 / 110 \mathrm{kV}$ to substation $400 / 110 \mathrm{kV}$. Measurements have shown that the flicker has a major impact and configuration system $110 \mathrm{kV}$. In some cases, exceeded values flicker effect, and therefore the final part of the article deals with the possibility of deployment of active filters low power.
\end{abstract}

\section{Key words:}

Flicker effect, Electric Arc Furnace, Static Var Compensator, STATCOM, Industrial Distribution Network

\section{Introduction}

In industrial distribution systems power quality is frequently influence by nonlinear loads. One of the most frequent phenomena is flicker effect, which exceed the permissible levels. Flicker effect in distribution systems is often exceeded as a result of the connection of electric arc furnaces, which exhibits high variable electrical power intake. These problems are often solved by the steel industries. Correct, however, resolving these issues involves three entities:

- Steel mills

- The distribution system operators

- The transmission system operator

All the listed entities are fundamentally involved in the formation of the undesired conditions. The problem with steel mills often lies in the absence of efficient filtration - compensation devices, running non-optimized production equipment and also the absence of modern technologies in the production process. Distribution system operators often do not provide sufficient large amount of short-circuit current at the Point of Common Coupling as a result of improper configuration of network infrastructure and lack of HV lines.

The problems caused by the transmission system associated with the operation of $220 / 110 \mathrm{kV}$ substations, which have significantly low short-circuit power at the $400 / 110 \mathrm{kV}$ substation. The problem may also be due to inappropriate design of the EHV / HV substation, which is due to the operation of only one transformer, which in turn reduces the short-circuit current.

\section{Voltage quality improvement}

To improve these situations, it requires the cooperation of stakeholders, which will be in gradual steps in order to contribute to the overall solution.

\section{A. Steel Mills}

Steel companies should invest in proper design of SVC devices with passive resonant harmonic filters. Positive results can be achieved with the optimum adjustment of the tap furnace inductors, thereby reducing the variability of power take-off.

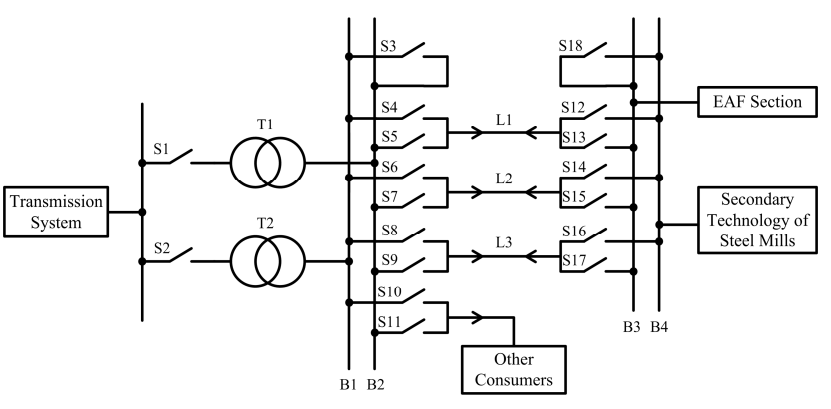

Fig. 1. Distribution system topology of case study.

The EAF with the part of the distribution network with low short circuit power has been study. Distribution system topology is shown in Fig 1. The case study was done fot six different network conections. Switching states are shown in table I.The EAF has been equipped 
with the SVC and four passive filters tuned to the 2, 3, 4, $5^{\text {th }}$ harmonics.

Measurement with different values of current, of short-circuit ratios at the PCC, of arc length and voltage ratios of the furnace transformer has been done to monitoring long-time flicker effect $P_{l l}$.

Table I. - Switching states for studied distribution system.

\begin{tabular}{|c|c|c|c|c|c|c|c|c|c|c|c|c|c|c|c|c|c|c|c|}
\hline & & \multicolumn{18}{|c|}{ Switching state } \\
\hline & & 1 & 2 & 3 & 4 & 5 & 6 & 7 & 8 & 9 & 10 & 11 & 12 & 13 & 14 & 15 & 16 & 17 & 18 \\
\hline \multirow{6}{*}{ 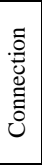 } & 1 & 1 & 1 & 0 & 0 & 1 & 1 & 0 & 1 & 0 & 1 & 0 & 1 & 0 & 0 & 1 & 0 & 1 & 0 \\
\hline & 2 & 1 & 1 & 0 & 0 & 0 & 1 & 0 & 0 & 1 & 1 & 0 & 0 & 0 & 0 & 1 & 1 & 0 & 0 \\
\hline & 3 & 1 & 1 & 1 & 0 & 1 & 1 & 0 & 1 & 0 & 1 & 0 & 1 & 0 & 0 & 1 & 0 & 1 & 1 \\
\hline & 4 & 1 & 0 & 0 & 0 & 1 & 0 & 0 & 0 & 1 & 0 & 1 & 1 & 0 & 0 & 1 & 0 & 1 & 1 \\
\hline & 5 & 1 & 0 & 0 & 0 & 1 & 0 & 0 & 0 & 1 & 0 & 1 & 1 & 0 & 0 & 1 & 0 & 1 & 0 \\
\hline & 6 & 1 & 1 & 1 & 0 & 1 & 0 & 0 & 0 & 1 & 0 & 1 & 1 & 0 & 0 & 1 & 0 & 1 & 0 \\
\hline
\end{tabular}

In order to illustrate the limits of regulation of flicker with the help of an SVC controlled by a classical regulator without a predictor we can show its Flicker Suppression Factor (F.S.F.), Fig. 2.

The results show low Flicker Suppression Factor SVC for this supply system. From an analysis of flicker it follows that its regulation has a limit due to time delay $\mathrm{Td}$ in the regulation loop of SVC.

\section{F. S. F. for PID regulator of SVC}

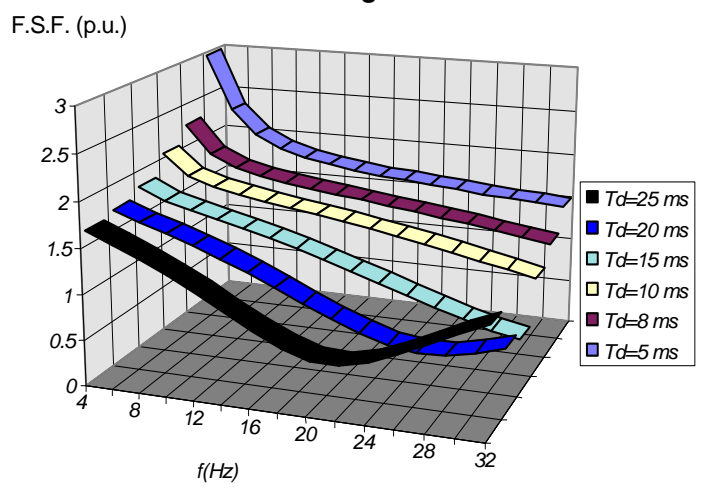

Fig. 2. Flicker Suppression Factor for SVC in operation.

Modifications of the technological processes leads to the result of relaxed Arcing. For example, the oxygen and gas burners, with the use of treated and preheat scrap steel or advanced control systems of electrodes. Lastly, measures should be deployed using active filter STATCOM with appropriate control strategy. The filter should respond to frequencies causing flicker effect.

\section{B. Distribution and transmission system operator}

The distribution system operators should systematically build the high voltage overhead lines with low impedance, and the possibility of parallel operation of several lines. The transmission system operator should despite today's popular unification proposal, should adapt the reconstruction of EHV/HV substation requirements of the area. The transmission system is currently moving away from the operation of $220 \mathrm{kV}$ system and replace it with a system of $400 \mathrm{kV}$. This change brings a number of advantages:

- Increasing short-circuit power

- Increasing transmission capacity
- Improvement of system stability

- Decreasing operating power losses

- Limiting of power quality problems

- Unification of transmission system

Let us focus on improving the quality of electricity, particularly flicker effect. Short-circuit power supplied by the $220 / 110 \mathrm{kV}$ substation at the connection to the customer's electric arc furnace (PCC) was around 700 MVA. EAF under these conditions caused enormously high flicker. To improve substantially contributed deployment SVC, but the flicker effect level was still high. Figure 5 shows the measured values of short-term flicker effect, PST to power EAF of $220 / 110 \mathrm{kV}$ substation. Values in place B represent point PCC.

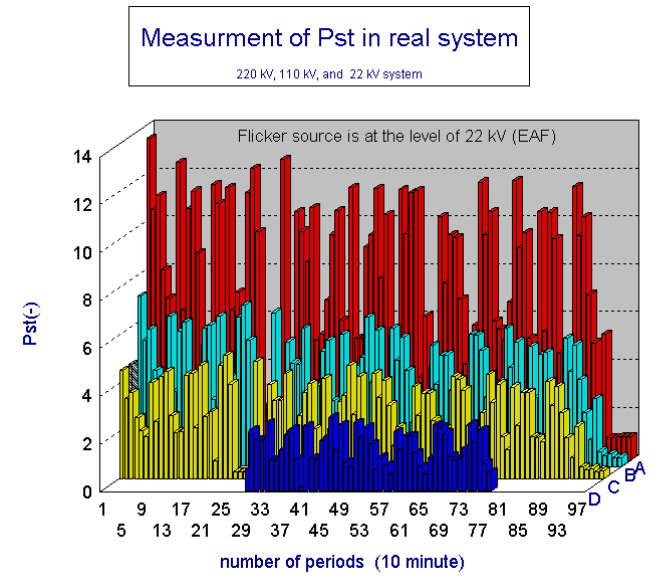

Fig. 3. Measurement of short-time flicker effect, point B represents PCC.

Reconstruction of the $400 \mathrm{kV}$ system brought significant increase in short-circuit power at PCC. Currently, the short-circuit power in PCC is in the range of 1200 to 2800 MVA MVA based on the configuration of 400/110 $\mathrm{kV}$ substation. Topology 400/110 kV substation and distribution system is shown in Figure 1. Table 1 shows the possible switching states involvement distribution system. For connection 1 and 2, there is no significant improvement in the short-term flicker effect. Connections 3-6 show a substantial improvement which has been achieved by the use of two $400 / 110 \mathrm{kV}$ or parallel connection of $110 \mathrm{kV}$. The measured values of short-term flicker effect are shown in Figure 4 for all connections.
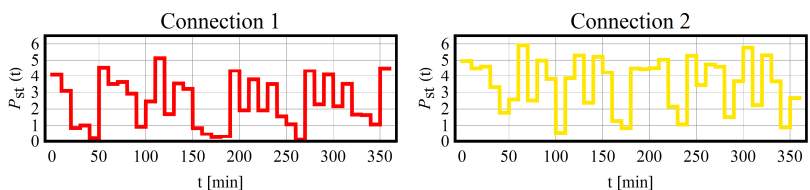

Connection 3
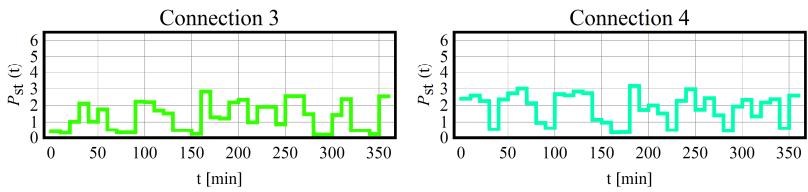

Connection 5
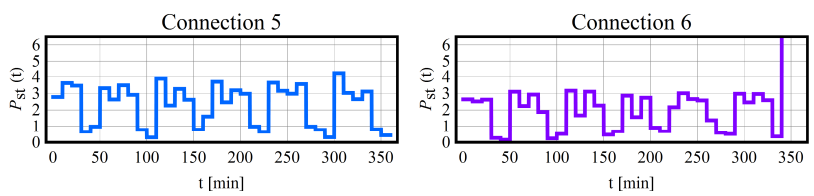

Fig. 4. Measurement of short-time flicker effect for 400/110 $\mathrm{kV}$ substation suplyment. 
Typically, the problem arise because in a substation with two transformers with a common power output rating of $700 \mathrm{MVA}$, with the actual consumption rating $150 \mathrm{MW}$. In this case, efforts to operate only one transformer, due to the losses, but this may contribute to the enhancement effects of flicker in a larger proportion. Proliferation of flicker effect is inappropriate in the operation of both transformers, where one connection is problematic and the other transformer connected to consumers. Following figure 5 shows the comparison of measured long-term flicker effect values for studied variants.

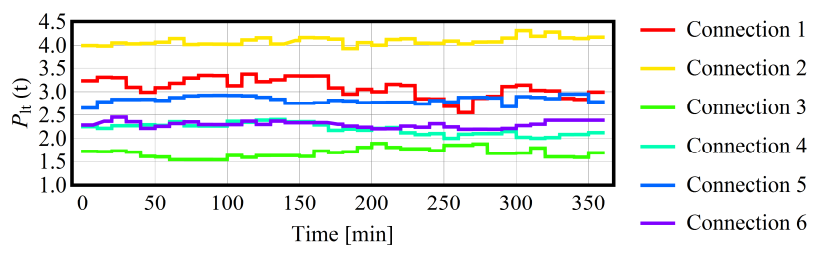

Fig. 5. Long-term flicker effect values for studied variants in PCC.

Cooperation between Steel Mills, Transmission System Operator and Distribution System Operator helps to improve long-term flicker effect. Evaluated values are shown in table II.

Table II. - Long-term flicker effect evaluation.

\begin{tabular}{|c|c|c|c|}
\hline $\begin{array}{c}\text { Measurement } \\
\text { point }\end{array}$ & $\begin{array}{c}220 \mathrm{kV} \\
\text { System }\end{array}$ & $\begin{array}{c}220 \mathrm{kV} \\
\text { System }+ \\
\text { SVC }\end{array}$ & $\begin{array}{c}400 \mathrm{kV} \text { System } \\
+ \text { SVC }\end{array}$ \\
\hline $\begin{array}{c}\text { Distributor } \\
\text { subst. }(110 \\
\mathrm{kV})\end{array}$ & $7,4-7,5$ & $4,2-4,3$ & $1,15-2,1$ \\
\hline $\begin{array}{c}\text { PCC }(110 \\
\mathrm{kV})\end{array}$ & $11,1-11,5$ & $6,3-6,5$ & $1,87-4,33$ \\
\hline
\end{tabular}

Applying these measures described, flicker effect problems in the distribution system, especially at low voltage level will be solved. In addition, the steel mills actions brought the improvements of production, higher productivity and lower power consumption per ton of steel. After applying the measures, the distribution systems meet the quality requirements of electricity in accordance with applicable legislation. Additional measures were taken to reduce losses and increase the flexibility and reliability of the distribution system. The level of flicker effect on the LV was managed to reduce the level of $\mathrm{P}_{1 \mathrm{t}} \leq$ 0.9. Measured values are shown in following figure 4.

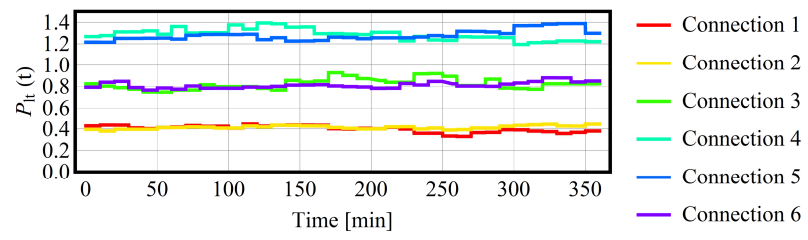

Fig. 6. Long-term flicker effect values for studied variants in low voltage level.

\section{Other possible measures}

Despite the implementation of strong measures the amount of long-term flicker in some circumstances exceed the permitted limits. As a modern solution would seem replacing the present SVC by new device STATCOM. Cost of construction equipment STATCOM are too high. Looks promising solution, which will be maintained SVC device to which it will be installed active filters low power. Possible active filter topology is shown in Figure 7. Low power active filter is technically possible by appropriate control strategies.

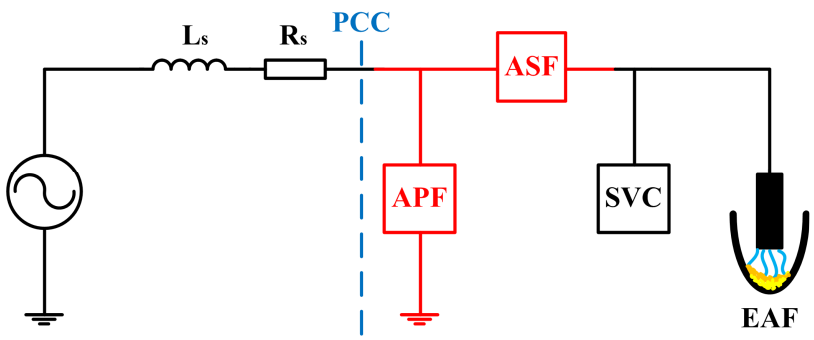

Fig. 7. Topology of the Active Serial Filter and Active Parallel filter

The control strategy of active filter in this case is based on the theory of instantaneous power. Control circuits active filters are primarily interested in voltage changes at frequencies that cause flicker. To determine the necessary power active filter simulation was performed based on the scheme of Figure 8. The scheme does not include installation SVC, because we suppose reactive power compensation and higher harmonics elimination (by SVC). Variable active power of EAF is simulated by Cassie-Mayr mathematic model of electric arc with variable arc length.

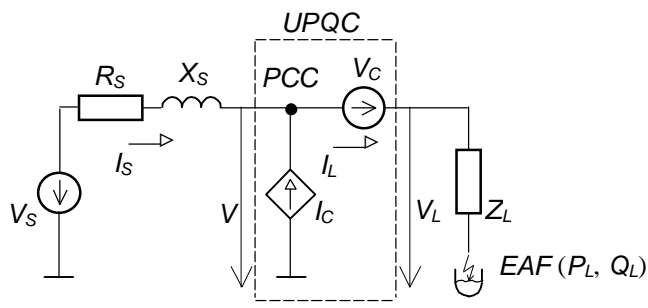

Fig. 8. Simulated circuit [3].

The result of the analysis of the compensatory performances active filters required for full compensation of voltage fluctuations. To suppress flicker effect, we should focus on the frequency range of units $\mathrm{Hz}$ to $35 \mathrm{~Hz}$. Figures 9 and 10 show the results of a required compensating power depending on the frequency of voltage fluctuations. 


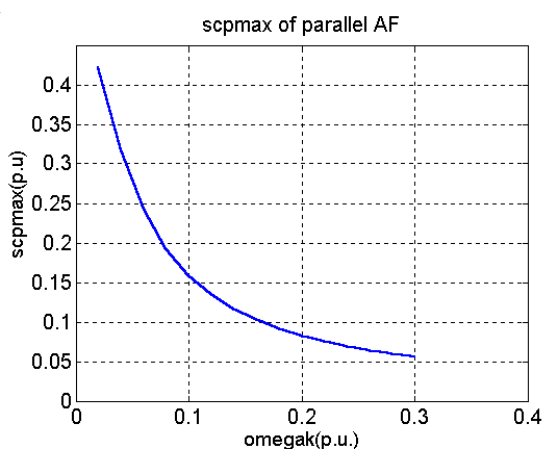

Fig. 9. Required compensating power depending on the frequency of voltage fluctuations for APF [3]

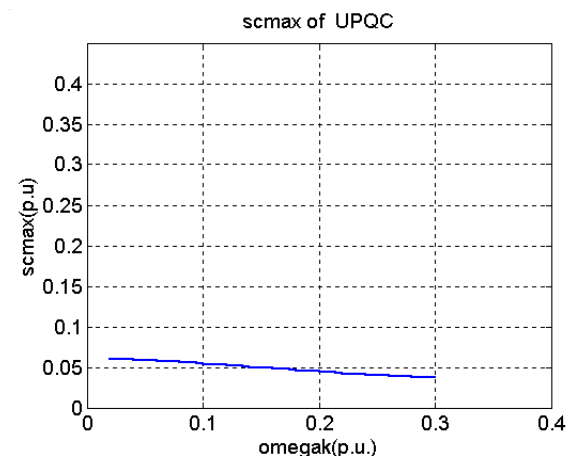

Fig. 9. Required compensating power depending on the frequency of voltage fluctuations for UPQC (Combined APF and ASF) [3]

It turns out that the use of a separate APF required for compensating power at $40 \%$ of rated power of EAF for low frequencies. A more efficient solution is to deploy UPQC (Unified Power Quality Conditioner), which requires compensating power only $7 \%$ of rated power of EAF. Currently under development such equipment for EAF type UHP with rated power $36 \mathrm{MW}$.

\section{Conclusion}

The article has shown the development of long-term values of flicker effect in industrial distribution network with a dominant of electric arc furnace. The introductory Parts were explained the benefits of the measures implemented. For a real improvement of the situation it is very important cooperation between the steelworks, the distribution system operator and the transmission system. If the collaboration would not work efficiently, there may be continuous damage to of one or more designated entity. The article shows the development of flicker effect in real situations where the number of measures in all participants. Despite favorable condition, however, a need for further restrictions flicker effect. As one of the last options were prospectively appears deployment of active filters with an appropriate control strategy.

\section{References}

[1] PEENS, Marius. Modelling and control of an electrode system for a three-phase Electric Arc Furnace. University of Pretoria, 2006. http://upetd.up.ac.za/thesis/available/etd04122007-145140/unrestricted/00dissertation.pdf.

Dissertation. University of Pretoria, Faculty of Engineering.
[2] TAVAKOLI Abdolreza, Mehdi EHSAN and Seyed Mohammad Tagie BATAHIEE. A SIMULINK Study of Electric Arc Furnace Inactive Power Compensation by Using STATCOM. Journal of Applied Mathematics: Islamic Azad University of Lahijan. 2006, vol. 3, no. 3.

[3] DOLEŽAL Jaroslav, TLUSTÝ Josef, VALOUCH Viktor: Control Strategies of Unified Power Quality Conditioner for Flicker Mitigation. In Proceedings of the 1st IFAC International Workshop on Advanced Control Circuits and Systems. Oxford: Elsevier, 2005, p. 1-6.

[4] CHANDRASEKHAR, S., J. BRAHMMAM and $M$. SRINU. Mitigation of Voltage flicker and reduction in THD by using STATCOM. International Journal of Electrical and Computer Engineering (IJECE). 2012, vol. 3, issue 1. DOI: 10.11591/ijece.v3i1.1951. 